\title{
Potential of Circular Design in Estonian SMEs and their Capacity to Push it
}

\author{
Markus VIHMA ${ }^{1 *}$, Harri MOORA ${ }^{2}$ \\ ${ }^{1}$ Estonian Academy of Arts, Põhja pst. 7, 10412 Tallinn, Estonia \\ ${ }^{2}$ Stockholm Environment Institute Tallinn Centre, Erika 14, 10416 Tallinn, Estonia
}

\begin{abstract}
While the capacities of larger enterprises enable them to adopt new circular design approaches and business models, small and medium-sized enterprises (SME) are also increasingly aware of the benefits of closing loops and improving resource efficiency. The SMEs in Estonia are confronted with several obstacles that hinder their circular design related actions. The organizational capacity and capability play a significant role in small businesses when developing concrete solutions for the circular economy, integrate those principles into their strategy and product development process and sustain those efforts. This paper aims to explore the SMEs' circular design capacity and capability for adopting new approaches in traditional small manufacturing companies who have a product-oriented focus and follow the dominant linear economy business strategy in Estonia. The circular design assessment method was developed to analyse a company's current status of circularity and evaluate the level of eco/circular design capacity. The results of the study show that the critical dimensions that are crucial for SMEs' ability to successfully perform circular design are related to their business strategy and planning, owners/manages leadership as well as ability to learn and cooperate and create relationships with external entities for internal dissemination.
\end{abstract}

Keywords - Circular economy; circular design; design capacity; SMEs

\section{INTRODUCTION}

Humanity seeks sustainability and circular economy has risen in popularity as it promises a way to combine the natural environment with needed improvements in our economic activities [1], [2]. The circular economy has been described as an industrial economy that relies on the "restorative capacity of natural resources" and aims to minimize waste, utilize renewable sources of energy and phase out the use of harmful substances [3].

While the integration of circular economy is a well-established policy vision in many countries [4] and on the European level [5], [6], much stronger commitment is required locally to reap the environmental benefits [7]. The practical steps that enterprises should take in order to fulfill the promise of circularity in a way that is aligned with their core activities and business requirements are less established [8]-[10].

Circular design - a specific description of more common terms like eco-design, design for the environment and sustainable design [11] - encompasses product development and new business models that lower environmental impact. It stems from two interconnected ideas: the closed-loop economy and 'design to re-design' thinking [1]. Circular design places also a

* Corresponding author.

E-mail address: markus.vihma@artun.ee 
strong emphasis on product life extension [12] in addition to 'designing out' waste [1]. It's a form of economic efficiency that emphasizes increasing the utilitarian value of input and reducing the overall output and can be best understood as an opposition to the conventional "take-make-dispose" logic of resource use [13].

While the capacities of larger enterprises facilitate the adoption of benefits from new circular products and business models, small and medium-sized enterprises (SMEs) are also increasingly aware of the benefits of closing loops and improving resource efficiency: saving material costs, creating competitive advantages and entering new markets [14]. However, moving towards new circular products and services requires fundamental change across the whole organization. It demands organizational strategy and structures that require that the company innovate in multiple areas.

Numerous barriers can hamper the implementation of circular design and economy practices by SMEs, such as lack of support from the supply and demand network and lack of capital [15], [16]. Setting aside the typical external factors such as the state's lack of support for long-term thinking that would give motivation to develop circular practices, there are also internal ones that matter. Circular products and services relate strongly to the capability (knowledge, technical skills and organizational capacity) and environmental culture of a small enterprise to manage innovation [15].

Compared to several other European Union (EU) member states, the circular economy is not integrated into national policies or strategies in Estonia. This is one of the reasons why the circular economy has been a fairly unknown concept among Estonian business sector and especially SMEs. However, since Estonia has a small and open economy, many SMEs are facing pressure to improve their economic performance, particularly their resource and energy efficiency. Although some improvements can be achieved through reorganizing the manufacturing processes, more proactive and export-focused SMEs have recognized that to stay competitive, they also must consider the circularity of their products. The SMEs in Estonia are confronted with significant obstacles that hinder their circular actions. Organizational capacity and capability play a significant role when developing the circular economy concept and integrating and maintaining it in the business and product development processes of small businesses. Developing one-off solutions alone does not lead to circular transformations and the organization must lead and support sustained effort over time.

During the past decade, new product development has increasingly been recognized among Estonian SMEs as a critical factor in ensuring business success and continued survival. In addition, the turbulent business environment and changing customer needs require new methods that bring successful new products to the marketplace. Traditional manufacturing SMEs, thus, provide an ideal setting to investigate small firm organizational capacity for switching from linear to circular product designs and operations.

This paper aims to identify the organizational capacity and capability for traditional small manufacturing enterprises in Estonia which have a product-oriented focus and follow the dominant linear economy business strategy to adopt circular design approaches. The question is whether their organizations support the development of circular designs or not and what could be improved for systematic integration of circularity in their businesses. Understanding of the current state of affairs in the industry is critical both in order to define future research and determine the requirements for supporting companies moving towards more circular products and business models and sustain them.

The authors also intend to relate the identified organizational barriers to capabilities, as the complexity of integrating sustainability and business demands an increased capability in managing constraints for disruptive changes and circular innovation. 


\section{InNovation and Product Development in Estonian SMEs}

SMEs represent $99.9 \%$ of all Estonian companies and they contribute to $76 \%$ of added value generated by all Estonian companies (this is $18 \%$ above the respective EU average) [17]. SMEs employ $79 \%$ of the population and make $75 \%$ of private sector investments [17]. The large majority of them feel confident enough to increase their turnover and market share [18]. The value added and employment rise of micro- and small enterprises has been especially fast.

On the whole, most of the SMEs operate in trade, accommodation and food services, manufacturing, agriculture, transport and logistics and building [19]. Typical manufacturing companies are still mostly operating in traditional (low technology) sectors. Many SMEs in Estonia are also engaged as subcontractors. The largest share of subcontractors comes from the manufacturing sector, where over $18 \%$ of SMEs act as subcontractors [20].

This is the reason why SMEs are not much engaged with product development and their turnover of new products is modest [21].

$44 \%$ of Estonian SMEs have carried out some process or product innovation and $34 \%$ have introduced changes in their management or marketing [21]. Only one third of SMEs have managed to implement those improvements without external help. Innovative entrepreneurs in Estonia are still behind the EU average when it comes to the growth of turnover of new products and services. The number of enterprises that introduced an innovation with environmental benefits is a mere $42 \%$ of the EU average [22].

SMEs play a significant role in the economy, and they have advantages in terms of flexibility and possible innovation capacity that put them into a central role in the implementation of circular economy in Estonia.

\section{Methods}

A two-fold approach was selected for the research. First, to get an overview of the general state of affairs among SMEs in Estonia, a questionnaire survey was used to learn about the awareness of circular economy and companies' proficiency with product development including environmental and circular product development. For that, an internet-based survey was sent out to 667 companies. The survey had a graph succinctly explaining the circular economy concept and questions to see if they are aware of what circular design is, what the perspectives of implementing it are and if and how it has been done at their companies.

Second, in-depth semi-structured group interviews, site examinations and background analyses were conducted with five case study companies to gather empirical understanding of their eco/circular design capacity. The five studied companies represented a cross-section of typical Estonian established and mature manufacturing SMEs (no start-ups were examined). For the sake of anonymity, the companies in this study are referred to as:

- The Subcontractor - a typical Estonian-owned contract manufacturer with a long tradition of offering high-quality and competitive pricing without an emphasis on developing their own products. However, with the now-changing market they have started to recognize the need for updating their offerings;

- The Designer - a small design company of employees/craftspeople, owned and managed by the designer;

- The Mature Local - a classical Estonian-owned eco-design-oriented company in a competitive market. They perform their own environment-oriented product 
development;

- The Group Manufacturer - a manufacturing facility owned by a foreign parent company. The company is technologically advanced and looking for ways to develop their product portfolio to rise from a mere manufacturing factory to a partner with high value offerings;

- The Group Member - a foreign-owned company of a Scandinavian group with close internal ties and interaction with other group members.

The assessment of the eco/circular design capacities of these selected SMEs was based on an assessment framework (Circular Design Audit) that was developed by the authors of this research to be used as a practical diagnostics tool also beyond this study [23]. The tool helps assess the existing strategy, organizational structure, processes and relevant design management aspects of the organization to identify the major needs, and possible weaknesses and strengths for business model and circular product development (see also Table 1). The assessment framework is based on elements of the so-called Innovation Diamond model [24] that has been widely used for measuring the innovation capability of organizations.

\section{TABLE 1. DimENSIONS AND FACTORS OF THE USED ECO/CIRCULAR DESIGN CAPACITY ASSESSMENT}

\section{Dimensions Factors}

The assessment looks at whether the organization has a strategy that supports innovation

Strategy and design as well as well-managed strategic planning process in place that supports it. It is beneficial to understand if the innovation and design is appreciated by entire organization and if there are mechanisms in place that effectively implement the company's strategy and values.

If the organizational structure encourages, rather than stifles, innovation and design through effective top-down, bottom-up, and lateral communication and coordination within the organization. Also, if the roles and responsibilities regarding the design process are clearly defined and whether management has put in place a system that encourages employees to bring forth new ideas or not.

Organization If the organization has the ability to manage its internal product design processes, mainly Processes \& procedures with the existence, robustness and flexibility of the organization's product development process.

\begin{tabular}{ll}
\hline Linkages & $\begin{array}{l}\text { If the company has access to knowledge, experience and skills in circular economy } \\
\text { outside the organization itself. For that, the assessment looks at the organization's ability } \\
\text { to cooperate and create relationships with external entities, such as customers, suppliers, } \\
\text { research institutions, consultancies, business partners, etc. }\end{array}$ \\
& $\begin{array}{l}\text { If the knowledge, skills and experience about circularity and circular products is being } \\
\text { developed systematically and moreover, shared across the organization for everyone to }\end{array}$ \\
learn from and improve on. If the organization is able to learn from its successes and \\
failures, gather external knowledge from outside and if it is committed to the training and \\
development of its employees.
\end{tabular}

Each of the above-mentioned dimensions was measured by a set of questions to evaluate and assess the organization's overall innovation and design management profile. Semistructured interviews were held with predefined questions about the above dimensions and additional inquiries were made depending on the need and profile of the company. A score from 1-3 was assigned to each of the specific questions where 1 indicated "exists," 2 "partly" and 3 "does not exist." 


\section{ReSUlts AND DiscuSSION}

\subsection{General Status Concerning the Environmental and Circular Product Design from Survey Results}

The number of companies who submitted their answers to the questionnaire survey was relatively low ( 21 companies of 667 polled). One of the reasons for a low response rate could be the fact that the subject matter is unfamiliar to the companies. Therefore, the low response rate could reflect the low awareness about circular economy and circular design among the general public. However, even with a low number of respondents, the following conclusions can still be made.

Nearly half (52\%) of the answered companies have between 10 and 50 employees (see Fig. 1).

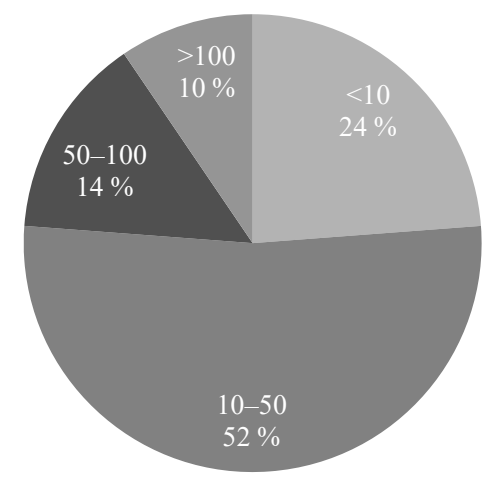

Fig. 1. Share of respondents by the number of employees in their companies.

Around $80 \%$ of the companies are engaged with product development at a certain level. Around $70 \%$ of companies claimed that they have considered environmental aspects concerning their products. However, only $30 \%$ of respondents claimed to have released products that are marketed as environmentally responsible. This may be because the majority of companies are focusing their environmental improvement efforts mainly on the manufacturing process. In addition, it may be caused by variances in the number of the companies' own products in the whole product range, as subcontracting is a common practice.

Among those SMEs who responded, the term "circular economy" is known (71\% of respondents) and more than half $(57 \%)$ of them see potential in implementing circular economy principles in their business models. The most common practices that companies already have applied have been designing for efficient manufacturing (focusing on improving the environmental performance of their production process) and resource conserving (choice and selection of circular materials). Product life extension and design for end of life recycling as circular design strategies have been used less often. The least used strategy was offering the product as a service (see Fig. 2).

The results of the questionnaire show that Estonian SMEs concentrate on simpler circular design solutions: product material choices and manufacturing processes improvements. Far 
fewer companies have applied circular design in its full potential or changed their business models to create long-lasting products and develop services that support them.

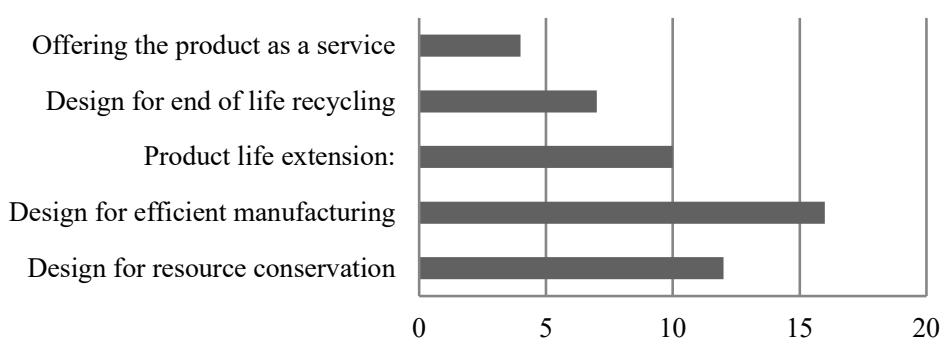

Fig. 2. Use of a circular design approach in the company's product development.

\subsection{The Organizational Capacity and Capability to Apply Circular Design from In-Depth Assessments}

The results of the circular design and product development capacity assessment of typical Estonian SMEs varied greatly among companies (see Fig. 3). The variances of circular design capabilities are the result of the nature of the companies and the business models their activities are based on, as well as leadership and creativity, type of ownership and resources (both human and financial).

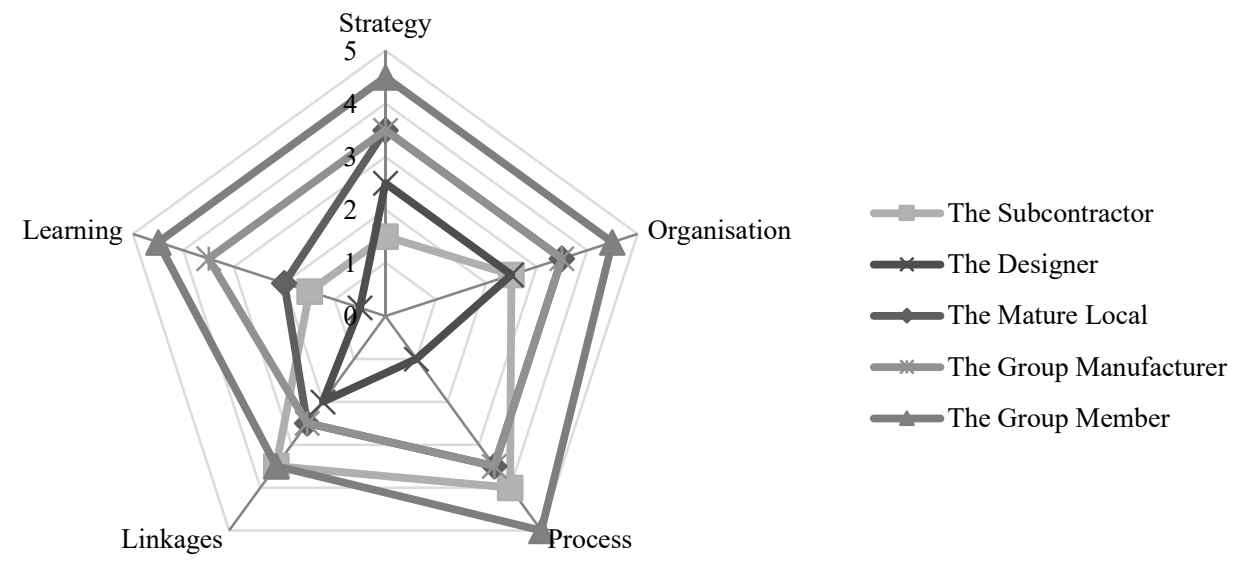

Fig. 3. The results of companies' circular design capacity assessment by dimensions.

\subsubsection{Business Strategy and Strategic Planning Process that Supports Circular Design}

The results of the assessment show that the companies that are owned by foreign capital (the Group Member and the Group Manufacturer) are more likely to have a well-defined business strategy and strategic planning process that supports circular design. Foreign-owned companies also tend to have a higher-level management culture. For example, the benefit of being a group member of an international consortium is that the parent company (from 
Scandinavia) requires that the subsidiary perform rigorous strategic thinking on environmental topics and circular design. However, the higher performers do not always use this strategic connection and potential as the strategic approach is largely limited with the application of environmental management systems, namely ISO 14001, and referring to the strategic documents developed in the headquarters. Therefore, the environmental concerns and routines (including the circular product development) are not always fully integrated into the local company management system.

The Mature Local has a clear understanding of the need for environmentally considerate product development, however that did not translate into systematic changes to the existing business strategy. In the case of the Designer, his/her own personal vision and convictions took precedence over the established strategy. The business strategy of the Subcontractor was clearly the least established.

\subsubsection{Organizational Structure and Culture}

All of the SMEs examined had relatively strong organizational setting. The Group Member and the Group Manufacturer scored the highest again due to well-established organizational structures in place. Those structures encourage innovation and design through effective topdown, bottom-up and lateral communication and coordination within the company. However, neither companies showed great results in creating the structure to allow higher level circular design. It means that they all are fairly classical manufacturers where mixed teams and skills for product development are mediocre. Nor have any of the studied companies systematically assessed their risks and opportunities to seek higher earnings with new business models or adapt to changing contexts.

\subsubsection{The Ability to Manage Internal Product Design Processes}

The existence, robustness and flexibility of the organizations' product development process were examined. All the assessed companies emphasized the environmental aspects of their manufacturing processes (e.g. energy- and resource efficiency). This is understandable because increasing their manufacturing efficiency has so far given the clearest benefits. Those companies that had a quality or environmental management system (ISO 9001 or ISO 14001) showed a higher ability to manage their manufacturing and product development processes. Therefore, the Group Member and the Group Manufacturer and to a lesser extent the Mature Local have the clearest system for communication, project management, client feedback and product development. Other companies are also procedural but less systematic and those functions are conducted ad hoc. An obvious example is the Designer. An exception is the Subcontractor whose main focus was on the quality management of the manufacturing process. That company's procedures related to product quality and innovation were lacking.

\subsubsection{Linkages - Ability to Cooperate and Create Relationships with External Entities}

The foreign-owned companies clearly had a greater ability to cooperate and create relationships, as they have the necessary network and the opportunity to gather knowledge. However, the study revealed that those companies do not always excel at creating linkages outside their companies to take full benefit of their opportunities. Either for benchmarking against competitors or tapping into new knowledge from networks or universities, the companies are not in isolation and perform within their local region. However, largely they rely upon their own experience and to a lesser degree on local contacts. All companies emphasized that it is very difficult to initiate mutual circular cooperation/contacts or 
industrial symbiosis partnerships with other companies, because there is no such culture in Estonia. At the same time, the companies also mentioned that it is difficult to find local experts and consultants for environmental and circular design. It is important to note that there is very little cooperation between Estonian universities and SMEs. The universities are seen as unsuitable partners for innovation or cooperation on eco/circular design projects, because they lack "entrepreneurial" and agile mindset as well as practical tools that are suitable for SMEs in developing their circular products.

\subsubsection{Learning - Ability Learn and Gather External Knowledge}

Learning varies in most of the assessed dimensions because of the existence of linkages and ability to internally disseminate information. Learning ability and the incorporation of external knowledge is heavily dependent on the context of the company and the quality of the contacts it has. The companies that are members of bigger groups or consortiums have clear advantages, as they have much better opportunities to seek relevant knowledge. Also, the implementation of standardized environmental management systems (ISO 9001 and ISO 14001) creates a framework for systematically gaining external knowledge and seeking opportunities. Still the experiences of the analysed companies show that the implementation of those standardized management systems can be merely formal and the established structure may not benefit them after all. Not always do they carry on to the innovation and design processes.

The Subcontractor, the Designer and the Mature Local have not paid attention to the systematic organizational learning from clients, their performance targets and market or larger socio-technological developments. Neither does what they have learned circulate through the company.

\subsection{Critical Dimensions of SMEs' Circular Design Capacity}

Based on the results of the study it can be said that the critical dimensions that are crucial for SMEs' ability to successfully perform circular design are:

- Relevant strategy and planning - this is a critical dimension of SMEs' circular design capacity, because creating and applying a strategic plans helps to define the necessary steps over time and lead the process. It is also important to periodically re-evaluate the strategy. The study showed that companies with foreign ownership are best positioned in terms of strategy. However, those advances are not sufficiently used and the strategies remain general without a proper internal ownership that could hinder the capacity for circular product development.

- Network integration - being part of a bigger consortium or network is highly beneficial to a company. As SMEs cannot individually possess all the resources and capabilities needed to develop circular design and new products, they have to rely on a network of partners. Being a member of an international consortium or having a wide network of business and other knowledge partners is highly advantageous as it creates a better foundation for a company to learn and gather experience.

- Learning process - the ability to learn and integrate external knowledge is a major dimension that ensures successful circular design. It comes from the fact that integrating the environmental and circular economy topics into the product development process requires a significant amount of additional knowledge and skills (e.g. ability to analyse products life cycle impacts, gathering and analysing environmental information, assessment of future developments and risks, analysing 
policy and legal developments, etc.) compared to a classical product development process that mostly looks at the user experience. As small companies do not generally have great resources to procure external knowledge and skills it is important to develop external collaborations that offer them.

- A very important driver of innovation and circular design for SMEs is owners and the managers' leadership. This is especially relevant in small companies where it is difficult to create advanced and resource-demanding management systems as well as well-established business strategies. Following their vision for the business, they drive the company's innovation and circular design activity with goals and consistent product development.

\section{Conclusions}

The purpose of this study was to identify the organizational capacity and capability for traditional SMEs in Estonia to adopt circular design approaches. SMEs play a significant role in the economy and therefore they are of key importance in the implementation of circular economy in Estonia.

The results of the study show that a relatively large share of SMEs have heard of circular economy and more than half $(57 \%)$ of them see potential in implementing circular economy principles in their business models. However, the Estonian SMEs still concentrate on simpler circular design solutions: mainly on manufacturing processes improvements and product material choices, such as choosing the raw materials with lower environmental impact.

The results of the circular design capacity assessment of 5 typical Estonian SMEs showed that eco/circular design capacity and capability depends on the nature of the companies and the business models that their activities are based on, leadership and creativity, type of ownership and resources (both human and financial). That's why the highest eco/circular design capacity was in those companies who belong to foreign owned international groups.

Compared to other companies the companies who are members of bigger groups or consortiums have a higher capacity in all assessed dimensions. Such companies tend to have a stronger management culture and strategic planning and therefore also clearer environmental policies and higher inclusion of environmental considerations in their production and product development. They also have a clear advantage in regards to cooperation and learning as they have much better opportunities to seek relevant knowledge. The smallest capacity to implement circular economy principles is in subcontracting companies who lack the necessary business strategy and thinking, internal product design processes, linkages and abilities to learn.

The study has helped to reveal the critical dimensions that are crucial for SMEs' ability to successfully perform circular design. The most significant are the existence of relevant strategy and planning as well as the leadership of the owners and/or the managers, especially in small companies where it is difficult to create advanced and resource-demanding management systems as well as well-established business strategies. As the implementation of eco/circular design requires a significant amount of additional knowledge and skills (e.g. ability to analyze products life cycle impacts, gathering and analysing environmental information, assessment of future developments and risks, analysing policy and legal developments, etc.) compared to a classical product development process then it is very important that the SME's would have the ability to learn and integrate external knowledge another crucial dimension that ensures successful circular design. And last but not least circular design approaches and the business models of circular economy require close 
cooperation and partnerships with other actors. As SMEs cannot individually possess all the resources and capabilities needed to develop circular design and new products, they have to be capable of creating partnerships and participate in relevant cooperation platforms and networks.

\section{REFERENCES}

[1] Murray A., Skene K., Haynes K. The Circular Economy: An Interdisciplinary Exploration of the Concept and Application in a Global Context. Journal of Business Ethics 2017:140:369-380. https://doi.org/10.1007/s10551-0152693-2

[2] Geissdoerfer M., et al. The circular economy - A new sustainability paradigm? Journal of Cleaner Production 2017:143:757-68. https://doi.org/10.1016/j.jclepro.2016.12.048

[3] The Ellen MacArthur Foundation. Towards a circular economy: Business rational for an accelerated transition. Cowes: The Ellen MacArthur Foundation, 2015.

[4] McDowall W., et al. Circular Economy Policies in China and Europe. Journal of Industrial Ecology 2017:21(3):651661. https://doi.org/10.1111/jiec. 12597

[5] Communication from The Commission to The European Parliament, The Council, The European Economic and Social Committee and The Committee of The Regions, a European strategy for data. Brussels: European Commission, 2020.

[6] Circular Economy Action Plan 2020. Luxembourg: European Commission, 2020.

[7] Ghisellini P., Cialani C., Ulgiati S. A review on circular economy: the expected transition to a balanced interplay of environmental and economic systems. Journal of Cleaner Production 2016:114:11-32.

https://doi.org/10.1016/j.jclepro.2015.09.007

[8] Bovea M. D., Pérez-Belis V. Identifying design guidelines to meet the circular economy principles: A case study on electric and electronic equipment. Journal of Environmental Management 2018:228:483-494. https://doi.org/10.1016/j.jenvman.2018.08.014

[9] Matschewsky J. Unintended Circularity? - Assessing a Product-Service System for its Potential Contribution to a Circular Economy. Sustainability 2019:11(10):2725. https://doi.org/10.3390/su11102725

[10] Sassanelli C., et al. Circular economy performance assessment methods: A systematic literature review. Journal of Cleaner Production 2019:229:440-453. https://doi.org/10.1016/j.jclepro.2019.05.019

[11] De Los Rios I. C., Charnley F. J. S. S. Skills and capabilities for a sustainable and circular economy: The changing role of design. Journal of Cleaner Production 2017:160:109-122. https://doi.org/10.1016/j.jclepro.2016.10.130

[12] Bakker C., et al. Products that go round: exploring product life extension through design. Journal of Cleaner Production 2014:69:10-16. https://doi.org/10.1016/i.jclepro.2014.01.028

[13] Moreno M., et al. A Conceptual Framework for Circular Design. Sustainability 2016:8(9):937. https://doi.org/10.3390/su8090937

[14] Lucchetti M. G., et al. The Role of Environmental Evaluation within Circular Economy: An Application of Life Cycle Assessment (LCA) Method in the Detergents Sector. Environmental and Climate Technologies 2019:23(2):238-257. https://doi.org/10.2478/rtuect-2019-0066

[15] Rizos V., et al. Implementation of circular economy business models by small and medium-sized enterprises (SMEs): Barriers and enablers. Sustainability 2016:8(11):1212. https://doi.org/10.3390/su8111212

[16] Ormazabala M., et al. Circular Economy in Spanish SMEs: Challenges and opportunities. Journal of Cleaner Production 2018:185(1):157-167. https://doi.org/10.1016/j.jclepro.2018.03.031

[17] Small Business Act Fact Sheet 2019. Luxembourg: European Commission, 2019.

[18] Enterprise Europe Network. SME growth forecast 2017-2018. Luxembourg: European Commission, 2017.

[19] Statistics Estonia 2019 [Online]. [Accessed 15.02.2020]. Available at https://www.stat.ee/

[20] Rozeik A. Restructuring in SMEs: Estonia. European Foundation for the Improvement of Living and Working Conditions, 2013:35.

[21] Kaarna K., et al. Eesti ettevõtete uuendusmeelsus ja innovatsiooni toetamise võimalused (Innovativeness of Estonian companies and opportunities to support innovation.) Report. Innovation studies. Tallinn: Ministry of Economic Affairs and Communications, 2015.

[22] The eco-innovation scoreboard and the eco-innovation index. European Commission 2018 [Online]. [Accessed 15.02.2020]. Available at https://ec.europa.eu/environment/ecoap/indicators/index_en

[23] Eco-design Audit - The Startegic Tool for Circular Business Development. Estonian Design Centre 2017 [Online]. [Accessed 15.02.2020]. Available from: https://media.voog.com/0000/0038/1850/files/Ecodesign-audit_manual_01.02.2019.pdf

[24] Tidd J., Bessant J., Pavitt K. Managing Innovation: Integrating Technological, Market and Organizational Change. Chichester: John Wiley \& Sons, 2005. 